\title{
Prevalence and Factors Associated with Quality of Life among Diabetic Men Living with Erectile Dysfunction
}

\section{Pulawit THONGTANG ${ }^{1, *}$, Warunee FONGKAEW ${ }^{2}$, Bannakij LOJANAPIWAT ${ }^{3}$, Nantaporn SANSIRIPHUN ${ }^{2}$ and Nonglak CHALOUMSUK ${ }^{2}$}

\author{
${ }^{1}$ Boromarajonani College of Nursing, Chiang Mai 50180, Thailand \\ ${ }^{2}$ Faculty of Nursing, Chiang Mai University, Chiang Mai 50200, Thailand \\ ${ }^{3}$ Faculty of Medicine, Chiang Mai University, Chiang Mai 50200, Thailand
}

('Corresponding author's e-mail: pulawit@yahoo.com)

Received: 27 March 2018, Revised: 4 November 2018, Accepted: 5 December 2018

\begin{abstract}
Diabetic erectile dysfunction (DED) is one of the most frequently occurring complications of diabetes mellitus (DM) in men, and past studies have usually overlooked the effect DED has on quality of life (QoL). The objectives of this study are to determine the prevalence of DED and to investigate QoL, and the factors that influence QoL, in Thai men who are living with DED. Five hundred and eighty-two Thai men living with diabetes who enrolled in the diabetic and general medical outpatient clinic at a tertiary hospital in the northern part of Thailand were surveyed to determine the prevalence of DED, as well as QoL and its influencing factors, for men living with DED. The average age of the men was 58.2 years old $( \pm \mathrm{SD}=10.1$, range $=34.3$ - 80 years old $)$. DED was found in 417 out of the 582 men $(71.5 \%)$. The International Index of Erectile Function (IIEF-5) mean score was $17.03( \pm \mathrm{SD}=3.47)$. The QoL was found to be at a moderate level $(\overline{\mathrm{X}}=95.42 \pm \mathrm{SD}=11.39)$. The QoL domains found to be at a good level were the psychological $(\overline{\mathrm{X}}=23.84 \pm \mathrm{SD}=3.42)$ and environmental domains $(\overline{\mathrm{X}}=31.4 \pm \mathrm{SD}=3.98)$, while domains found to be at a moderate level were the social relationships $(\overline{\mathrm{X}}=10.77 \pm \mathrm{SD}=1.93)$ and physical domains $(\overline{\mathrm{X}}=24.9 \pm \mathrm{SD}=3.13)$. The mean score of the QoL of men living with DED was lower than that of men without DED. The most important factor associated with poor QoL was severity of DED, while men who have a good QoL tend to have a higher education level and more frequent sexual intercourse $(p<0.05)$. The study showed that the prevalence of erectile dysfunction in Thai men living with DED was high. DED has a moderate impact on QoL, especially on the social relationship domain. The results suggest the importance of screening for DED in clinical settings for early detection of, and creating supportive strategies for treating men with, diabetes mellitus.
\end{abstract}

Keywords: Prevalence, Quality of life, Diabetic erectile dysfunction, Diabetic men

\section{Introduction}

Diabetic erectile dysfunction (DED) is one of the most common complications of diabetes mellitus (DM). DED was reported to affect more than $50 \%$ of men with DM in both Western and Asian countries [1-4]. The pathogenesis of DED can be derived multifactorially from physical and psychological causes, including diabetic neuropathy, endothelial dysfunction, reform structure of the corporeal tissue, psychogenic components, and hormonal changes [5,6]. These causes can lead to not only a high prevalence, but also to a more severe degree, of erectile dysfunction when compared to men without DM $[2,7]$. DED can greatly disturb the sex life of men of almost all ages $[1,2,8]$.

The impact of DED is related to the quality of life (QoL). Interviews from a qualitative study show that men with DED view this problem not as a health issue, but as an issue that disturbs their whole life [9]. Living with erectile problems has a negative impact on men's holistic wellbeing [10], not only to 
http://wjst.wu.ac.th

men's physical health, but also to their psychological health and their relationships with their partners. Previous literature emphasized that the impact of DED is both psychological and social $[7,11,12]$. Men encounter mental issues such as anxiety, depression, loss of confidence, and loss of self-esteem [3,11,12]. Socially, men face deteriorating relationships and marital tension due to lack of sexual satisfaction [13]. However, in the other domains, the impacts of DED have yet to be sufficiently investigated or explained.

Based on the literature, QoL was associated with several factors, including personal background characteristics, the presence of diabetic complications, and clinical characteristics (e.g., severity of erectile difficulty) [14-18]. A review of Fatt [16] showed that age, education level, and marital status influence QoL. Younger men with erectile problems were found to have a poorer QoL when compared to men of similar age who do not suffer from impotence. Most of the previous studies have connected declining QoL with diabetic complications (such as peripheral neuropathy, poor visual acuity, diabetic ulcers on the foot, and renal and cardiac complications). Men of all ages who had a comorbid illness in addition to erectile problems were found to have poorer QoL compared to those without a comorbid illness [15]. All findings pointed out that men with DED showed a significant decline in physical function, which is one of the more severe clinical conditions of DED [14,17,18]. Moreover, the severity of erectile difficulty and IIEF score have frequently been reported as a major factor related to QoL [14$18]$.

Most of the previous studies on the prevalence of erectile dysfunction in Thailand were not concerned specifically with diabetic patients. Thus, an investigation of DED's magnitude among men living with DM is well needed in Thailand. There is less awareness of DED in DM men handling these issues. The salient issue of disrupted sexual function may have influence on men and their relationships to their partners in both non-intimate and intimate ways, which could continue to cause problematic clinical avoidance and worsening of QoL. Thus, the wide impact of DED on QoL among men living with DM needs to be further investigated.

This descriptive-correlational study seeks to determine the prevalence of DED among diabetic men and to assess their QoL and its associated factors. According to the World Health Organization, QoL is conceptualized as having 4 domains: physical, psychological, social relationships, and environmental [19]. The findings of this study could provide better knowledge and understanding of QoL among Thai men living with DED. The obtained findings can be used to compare with the related evidence and global studies.

\section{Materials and methods}

\section{Data collection}

This study is the quantitative part of a mixed method study. The population in this study was diabetic male patients who enrolled in the diabetes outpatient clinic and medical outpatient clinic in a tertiary hospital in the northern part of Thailand during January to June, 2017. The number of the target population in this study was estimated according to numbers in previous studies about the prevalence of DED with an error of 5 and a $95 \%$ confidence level [20,21]. Thus, the number of diabetic men surveyed for DED was approximately 600. Five hundred and eighty-two men who had lived with DM for at least 1 year, aged 30 years old and older, and had sexual activity within the last 6 months were selected. Men with a history of severe mental illness, such as schizophrenia or cognitive impairment, as well as those with serious medical complications, such as prostate cancer or paralysis, were excluded.

This study was approved by the Research Ethics Committee (REC) of the Faculty of Nursing and the Faculty of Medicine, Chiang Mai University. Data was collected after obtaining either written or verbal consent from each subject. The aims and process of the study were explained to each individual. The explanation of their rights and confidentiality were also noted.

Data was collected using 2 standard demographic questionnaires in Thai. The prevalence and severity of DED was collected by the Thai version of the IIEF-5 (International Index of Erectile Function5) [22]. The Cronbach's alpha value for the Thai version of IIEF-5 was tested at $=0.817$. This questionnaire was scored on a 5-point ordinal scale (1 to 5) in the domain of sexual function. It took approximately $5 \mathrm{~min}$ to complete. DED was diagnosed if the patient had a score of 21 or lower. The 
http://wjst.wu.ac.th

severity of DED was grouped as follows: severe ED ( 0 - 7 equates), moderate ED (8 - 11 equates), mild to moderate ED (12 - 16 equates), mild ED (17 - 21 equates), and no ED ( 22 - 25 equates).

A 26-item Thai version of the WHOQOL-BREF-THAI questionnaire [23] was used to assess QoL. This questionnaire includes 2 items for general health and quality of life, and 24 items for the 4 domains of QoL, namely physical health (7 items), psychological state (6 items), social relationships (3 items), and environment (8 items). Items were rated on a 5-point Likert scale, ranging from 1 to 5. The Cronbach's alpha value for the WHOQOL-BREF-THAI questionnaire was $=0.867$. The scores were divided as follows: poor quality of life (26 - 60), fair quality of life (61 - 95), and good quality of life (96 - 130). It took $15 \mathrm{~min}$ to complete the questionnaire.

\section{Data analysis}

Descriptive statistics were used to analyze the demographic data, prevalence of DED, and QoL scores. Descriptive statistical information was presented as frequencies, percentages, means, and standard deviations. Regression analysis was applied to measure the association between the factors and the QoL level. All reported $p$-values are 2-sided and deemed statistically significant at $\alpha=0.05$.

\section{Results}

The subjects were between 34 and 88 years old, with DED men (58.5 years old) slightly older than non-DED men (54.9 years old). The largest group of DED men had graduated secondary school $(27.8 \%)$. The results showed that income ranged over 20,000 THB, with the non-DED group (54.5\%) earning slightly higher income than the DED group (46\%). $47.7 \%$ of the DED group have had DM for a longer duration (5 - 15 years). Blood sugar levels of both groups ranged from 126 to $180 \mathrm{mg} / \mathrm{dL}$, with no significant difference found between non-DED men $(135.5 \pm 35.2 \mathrm{mg} / \mathrm{dL})$ and DED men $(137.6 \pm 40.4$ $\mathrm{mg} / \mathrm{dL})$. However, the majority of non-DED men had blood sugar levels ranging from $141-180 \mathrm{Mg} / \mathrm{dL}$ $(32.6 \%)$, while the blood sugar levels of DED men was found to range from $181-250 \mathrm{Mg} / \mathrm{dL}(31 \%)$. The findings showed the HbA1C of the DED group (7.5 $\pm 1.5 \mathrm{mg} \%)$ was slightly greater than that of the non-DED group $(7.1 \pm 1.5 \mathrm{mg} \%)$. Most DED men were found to be in the group of $8-10 \mathrm{mg} \%(33.2 \%)$ $\mathrm{HbA1C}$, while non-DED men were found to be in the group of $5.8-7 \mathrm{mg} \%(41.2 \%) \mathrm{HbA1C}$. Hypertension was found in both the non-DED group (57.6 \%) and DED group (60.2\%). Only $1.2 \%$ of the non-DED group and $2.9 \%$ of the DED group were reported to have depression. In terms of sexual activity (Table 1), non-DED men had a significantly higher average frequency of sexual intercourse compared to DED men $(4.7 \pm 3.9$ vs. $3.1 \pm 3.1$ times/month $)$. The most significant portion of the nonDED group (40.6\%) had sexual intercourse 4 - 7 times/month, while most of the DED group (53.2 \%) had sexual intercourse 2 - 3 times/month. The record also showed that DED men performed masturbation $(30 \%)$ more than non DED men $(21.8 \%)$.

Table 2 illustrates the prevalence and severity of DED. In this study, a total of 582 male respondents included 165 without DED and 417 with DED. Therefore, the prevalence of DED among Thai men living with DM was $71.65 \%$. The findings also revealed that, among 417 DED men, most men had mild DED (55.9\%; $\mathrm{n}=233)$, followed by mild to moderate DED $(37.4 \% ; \mathrm{n}=156)$, moderate DED $(6.2 \% ; n=26)$, and severe $\operatorname{DED}(0.5 \% ; n=2)$. 
http://wjst.wu.ac.th

Table 1 Demographic characteristics of the Non-DED and DED subjects studied $(\mathrm{N}=582)$.

\begin{tabular}{|c|c|c|c|c|c|}
\hline & \multicolumn{2}{|c|}{ Non-DED } & \multicolumn{2}{|c|}{ DED } & \multirow{2}{*}{$p$-value } \\
\hline & $N=165$ & $(\%)$ & $\mathbf{N}=\mathbf{4 1 7}$ & $(\%)$ & \\
\hline Depression history & 2 & $(1.2)$ & 12 & $(2.9)$ & 0.237 \\
\hline Hypertension & 95 & (57.6) & 251 & $(60.2)$ & 0.562 \\
\hline T1DM & 16 & (9.7) & 32 & (7.7) & 0.559 \\
\hline T2DM & 149 & $(90.3)$ & 385 & $(92.3)$ & 0.031 \\
\hline \multicolumn{6}{|l|}{ Duration of having DM } \\
\hline Below 5 years & 60 & (32.7) & 93 & (20.1) & \\
\hline $5-15$ years & 71 & (39.4) & 210 & $(47.7)$ & \\
\hline 15 years above & 34 & $(18.2)$ & 114 & (24.7) & \\
\hline Age $($ mean \pm SD) $[$ range] & \multicolumn{2}{|c|}{$54.9 \pm 9.3[34-74]$} & \multicolumn{2}{|c|}{$58.5 \pm 9.9[34-88]$} & $<0.001$ \\
\hline Current blood sugar level (mean $\pm \mathrm{SD}$ ) & \multicolumn{2}{|c|}{$135.5 \pm 35.2$} & \multicolumn{2}{|c|}{$137.6 \pm 40.4$} & 0.565 \\
\hline $\mathrm{HbA1C}($ mean $\pm \mathrm{SD})$ & \multicolumn{2}{|l|}{$7.1 \pm 1.5$} & \multicolumn{2}{|l|}{$7.5 \pm 1.5$} & 0.004 \\
\hline $\mathrm{BMI}($ mean $\pm \mathrm{SD})$ & \multicolumn{2}{|l|}{$27 \pm 4.2$} & \multicolumn{2}{|l|}{$27 \pm 5$} & 0.939 \\
\hline Number of SI meaning (mean \pm SD) & \multicolumn{2}{|l|}{$4.7 \pm 3.9$} & \multicolumn{2}{|l|}{$3.1 \pm 3.1$} & $<0.001$ \\
\hline
\end{tabular}

Table 2 Prevalence and severity of DED $(n=417)$.

\begin{tabular}{cll}
\hline \multicolumn{1}{c}{ IIEF-5 score } & Frequencies & Percentage \\
\hline $17-21:$ Mild erectile dysfunction & 233 & $55.9 \%$ \\
$12-16:$ Mild to moderate erectile dysfunction & 156 & $37.4 \%$ \\
$8-11:$ Moderate erectile dysfunction & 26 & $6.2 \%$ \\
$5-7 \quad$ : Severe erectile dysfunction & 2 & $0.5 \%$ \\
\hline
\end{tabular}

As shown in Table 3, the QoL among the majority of men living with DED is in 2 groups: moderate level $(50.6 \% ; n=211)$ and good level. Regarding the QoL domains, the Table illustrates that most DED men $(71.7 \%, \mathrm{n}=299)$ report that their QoL in the physical domain is at a moderate level $($ mean $=95.42$ \pm 11.39). For the psychological domain, social relationships domain, and environmental domain, the majority of men living with DED presented their QoL at a moderate level $(64 \%, \mathrm{n}=267)$ or good level $(66.4 \%, \mathrm{n}=277)$.

Table 3 QoL among men living with DED $(n=417)$.

\begin{tabular}{lllll}
\hline \multirow{2}{*}{ Variables } & \multicolumn{4}{c}{ Level of QoL } \\
\cline { 2 - 5 } & $\begin{array}{l}\text { Low } \\
\text { (Percentage) }\end{array}$ & $\begin{array}{l}\text { Moderate } \\
\text { (Percentage) }\end{array}$ & $\begin{array}{l}\text { Good } \\
\text { (Percentage) }\end{array}$ & $\begin{array}{l}\text { Mean } \\
\text { (SD) }\end{array}$ \\
\hline Total QoL & 0 & $211(50.6 \%)$ & $206(49.4 \%)$ & $95.42( \pm 11.39)$ \\
Physical domain & 0 & $299(71.7 \%)$ & $118(28.3 \%)$ & $24.90( \pm 3.13)$ \\
Psychological domain & $2(0.5 \%)$ & $188(45.1 \%)$ & $277(54.4 \%)$ & $23.84( \pm 3.42)$ \\
Social relational domain & $26(6.2 \%)$ & $267(64.1 \%)$ & $124(29.7 \%)$ & $10.77( \pm 1.93)$ \\
Environmental domain & 0 & $140(33.6 \%)$ & $277(66.4 \%)$ & $31.4( \pm 3.98)$ \\
\hline
\end{tabular}


http://wjst.wu.ac.th

Table 4 shows the association between various factors and QoL by applying multiple linear regressions. The results showed education $(B=1.690)$ and frequency of sexual intercourse $(B=2.030)$ have a positive influence on QoL $(p<0.05)$. This finding suggests that higher education level and more frequent sexual intercourse result in better QoL among males $(p<0.05)$. Moreover, stepwise regression technique was applied to predict factors that negatively influence the QoL of DED men. The results indicate that men with a higher BMI level $(\mathrm{B}=-1.442)$, and smokers $(2.755)$ would have a lower QoL. Additionally, DED men with a history of depression $(\mathrm{B}=-8.447)$ and those who masturbate more frequently would have lower QoL $(\mathrm{B}=-3.552, p<0.05)$.

Table 4 The influence of various factors on QoL of DED men.

\begin{tabular}{lllll}
\hline & \multicolumn{2}{c}{ Full model (Enter) } & \multicolumn{2}{c}{ Stepwise } \\
\cline { 2 - 5 } & Beta & $\boldsymbol{p}$-value & Beta & $\boldsymbol{p}$-value \\
\hline (Constant) & 97.746 & $<0.001$ & 104.540 & $<0.001$ \\
Age range & 0.294 & 0.692 & & \\
Educational level & 1.690 & 0.001 & 1.096 & 0.008 \\
BMI range & -0.992 & 0.073 & -1.442 & 0.006 \\
Smoking status & -2.170 & 0.001 & -2.320 & $<0.001$ \\
Number of SI & 2.030 & 0.004 & & 0.002 \\
Masturbation & -3.961 & 0.364 & -3.552 & 0.006 \\
\hline
\end{tabular}

Table 5 The relationship between quality of life and severity of DED.

\begin{tabular}{|c|c|c|c|c|c|c|}
\hline & DED & $\begin{array}{l}\text { Physical } \\
\text { domain }\end{array}$ & $\begin{array}{l}\text { Psychological } \\
\text { domain }\end{array}$ & $\begin{array}{c}\text { Social relational } \\
\text { domain }\end{array}$ & $\begin{array}{l}\text { Environme } \\
\text { ntal domain }\end{array}$ & $\begin{array}{l}\text { Total } \\
\text { QoL }\end{array}$ \\
\hline \multicolumn{7}{|l|}{ DED } \\
\hline Physical domain & -0.055 & & & & & \\
\hline Psychological domain & $-0.102^{*}$ & $0.332^{* *}$ & & & & \\
\hline Social relational domain & $0.111^{*}$ & $0.389^{* *}$ & $0.372^{* *}$ & & & \\
\hline Environmental domain & $-0.097^{*}$ & $0.334^{* *}$ & $0.423^{* *}$ & $0.413^{* *}$ & & \\
\hline Total QoL & -0.088 & $0.551^{* *}$ & $0.477^{* *}$ & $0.588^{* *}$ & $0.642^{* *}$ & \\
\hline
\end{tabular}

**. Correlation is significant at the 0.01 level (2-tailed).

*. Correlation is significant at the 0.05 level (2-tailed). 
The relationship between QoL and the severity of DED is presented in Tables 5 and 6. The correlation matrix shows that the severity of DED was statistically significant, with the social relational domain $(r=-0.111)$, psychological domain $(r=-0.102)$, and environmental domain $(r=-0.097)$ at the level of 0.05 , while no relationship was found between DED and the physical domain or the overall QoL $(p>0.05)$. According to sign of the coefficient, QoL and the severity of DED had a negative relationship. The results indicate that a higher severity of DED is associated with a lower QoL, which is found to have the greatest effect on the social relationships domain, followed by the psychological domain and the environmental domain. A regression analysis was applied to find the association between severity of DED and QoL domains. Table 6 shows that mild DED resulted in lower physical, psychological, and social relationship domains of QoL at the level of 0.01, while mild to moderate DED had influence on the psychological domain at the level of 0.01 . Moderate DED had influence on the social relationship domain at the level of 0.05 . The results demonstrate that men who live with a lower severity of DED experience a bigger impact on their QoL than those who have a high severity.

Table 6 The association between quality of life domains and severity of DED by regression analysis.

\begin{tabular}{llll}
\hline QoL Domain & Severity of DED & $\mathbf{B ~ ( 9 5 \% ~ C I ) ~}$ & $\boldsymbol{p}$-value \\
\hline Physical domain & Mild DED & 0.220 & $0.001^{* *}$ \\
Psychological domain & & 0.299 & $<0.001^{* *}$ \\
Social relationship domain & & 0.277 & $<0.001^{* *}$ \\
Environmental domain & Mild to moderate DED & -0.092 & 0.235 \\
\hline Physical domain & & 0.395 & 0.481 \\
Psychological domain & & 0.009 & $<0.001^{* *}$ \\
Social relationship domain & & 0.053 & 0.918 \\
Environmental domain & Moderate DED & 0.319 & 0.597 \\
Physical domain & & 0.127 & 0.189 \\
Psychological domain & & 0.408 & 0.486 \\
Social relationship domain & 0.154 & $0.012^{*}$ \\
Environmental domain & & 0.429 \\
\hline
\end{tabular}

**. Correlation is significant at the 0.01 level (2-tailed test).

*. Correlation is significant at the 0.05 level (2-tailed test).

\section{Discussion}

This study indicated that there is a high prevalence of DED among diabetic male patients attending outpatient departments of diabetic clinics in the northern part of Thailand. The results showed that more than half of the subjects in this study $(71.6 \%)$ had DED, which appears to be similar to the prevalence of DED in other countries. Previous Asian studies found that the estimated prevalence of DED among men living with DM varies from 50 - $97 \%[4,11,24]$. However, most of the DED found in previous studies was of a mild to moderate or moderate level, which is a higher severity compared to the majority found in this study $[4,11,24]$. The findings of our study showed that most of the subjects with DED have mild DED $(55.9 \%)$. The variance in prevalence may have resulted from a variety of study settings and differences within the subject population. A possible explanation for this difference is that the subjects in this study were clinically diagnosed as having DM. The subjects in our study were treated and had wellcontrolled blood sugar levels, which relates to a reduced occurrence of DED.

As regards QoL, men in our study demonstrated a moderate level of general QoL, which is consistent with previous studies $[11,14,15,17,25]$. However, only 1 previous study used WHOQoL-Bref to investigate general QoL [8]. The findings were consistent with our study, in that most men living with DED had moderate levels of QoL. This could be explained by the fact that the majority of subjects in our 
http://wjst.wu.ac.th

study believed their declining QoL to be linked to their diabetic clinical condition. The mean age of the subjects was 58.5 years old, which caused subjects to believe that their erectile problems were just the nature of old age [26]. Moreover, the majority of men in our study had mild DED, which was not strong enough to make them rate their QoL as poor.

Although the QoL measure used in previous studies differed from the one used in the current study, SF-36 is accepted as an alternative measure of the effect of DED on QoL. Most previous studies indicated a decline in the psychological domain among men who have DED. Erection problems cause men living with DED to have less confidence in life and in performing sexually $[9,19]$. In contrast to other studies, the majority of men in our study presented their psychological domain as good. This can be explained by the fact that most men in our study have mild DED, with only very few $(0.5 \%)$ reporting severe DED. Men with DED in this study indicated that they had been able to have sexual intercourse at least within the preceding 6 months. Some of them performed masturbation and had a high frequency of sexual intercourse. This is different from the group of men from the previous study, in which some had severe DED and were unable to have sexual intercourse. Still able to have sexual intercourse, $67 \%$ of men in our study reported a moderate level in the socio-relationship domain. Even though their average age is high, their points of view on the place of sex in a relationship varies. For some, sex is important to their partner in their relationship as an indicator of their love. Thus, the subjects worried that their partners might think they didn't love them anymore [27]. This finding is supported by its congruence with the DED study in India, which also reported a good level in the social relationship domain; it was claimed this was because most of the participants in their study were elderly. Usually, the elderly are busy with family activities, such as caring for their grandchildren [11].

The only previous study to investigate the environmental domain illustrated that men living with DED had a moderate QoL in the environmental domain [11]. Our findings present a different outcome for the environmental domain. The environmental domain is shown to be at a good level. The explanation for this finding is that all subjects in the study have health insurance. Moreover, the average score for receiving information is high (mean $=4.64)$. This means that the subjects have full access to receive news and information from media, such as the internet and television. Most of them also have income, pension, and aging subsistence allowance.

The findings of our study regarding factors associated to QoL shared the same results as previous studies [14-18]. Our study demonstrates that having sexual intercourse and performing masturbation have a positive influence on QoL. Age is considered as a non-manipulated factor that can lower QoL. The severity of DED, BMI, and smoking status are manipulated factors that also reduce QoL. In contrast, our study failed to show a significant association between the duration of having DM and DED.

In this study, the severity of DED is negatively associated with QoL. More severe DED results in a greater decline of QoL level. The association between the severity of erectile difficulty and QoL in this study highlights that mild DED has a greater impact on the QoL than a higher severity of DED. The greatest impact is on the physical, psychological, and social relationship domains. However, mild to moderate and moderate DED have influence only on the psychological and social relationship domain. This could relate to the duration of having DED and self-adjustment, as mild DED is generally seen in the early stages of erectile difficulty [28]. Subjects in the early stages of erectile difficulty may need to cope with a notable decrease in their sexual performance, as well as a perceived loss of manhood and gender role, e.g., the role of husband [16,29]. Perhaps this could explain why it is associated with reduced QoL, as they could not sexually satisfy their partners [30], whereas those who have more severe DED are familiar and have more experience adjusting to their impotence, as DED is a chronic condition that develops over time [31]. Nevertheless, the findings of our study indicate that most men living with DED have concerns about their social relationships, especially marriage. Erectile problems also cause a problem with their role as a husband, since they cannot satisfy their partners' desires [13,14,29]. This is further evidence that men who have erectile difficulty need support and understanding about their sex lives from both their partners and their health care providers.

In the Thai context, male potency is linked to superiority and power [32,33]. This might be described by the connection between a man's reproductive abilities and his sexual powers. As Thai men perceive a social expectation for Thai men to be good sexually, they concentrate on their sexual ability, 
http://wjst.wu.ac.th

namely on erectile ability [34]. Therefore, sexuality and sexual desire is an integral feature of Thai notions of maleness. The loss of the ability to have a spontaneous erection is likely to cause a sense of loss of masculinity among men. Loss of masculinity in men with DED can lead to stress, loss of selfesteem, loss of self-confidence about having sexual intercourse, and fear of losing a relationship, all of which affect their quality of life [35-37]. In our study, DED is found to be a major factor for declining QoL among men living with diabetes.

This study adds to the available knowledge on the association of the severity of DED to quality of life domains, and highlights particularly the influence of a low severity of DED. Findings from this study present the impact of severity of DED on each domain of QoL.

\section{Recommendations}

This study showed that the QOL of men with DED was at moderate level, which means that men with DED should have a clear plan for improving their quality of life. Such a plan would potentially include the following:

1) The findings suggest that routine screening for erectile difficulty among men living with diabetes is important. All male patients with DM should be evaluated for DED and treated. Early detection of DED could provide support for them and prevent a declining QoL. Then, once the assessment is completed, health care providers can pinpoint specific educational needs for the patient and their partner. In Thai culture, discussing sexual health can be uncomfortable for both nurses and male patients. Embarrassment is often cited as a major barrier to asking about sexual information. Particularly, female nurses may find it difficult to discuss sexual behavior with male patients [38]. Considering sexual information as an integral part of the patient's holistic health may help nurses to overcome this problem. In addition, nurses should be trained in effective communication skills for discussing sexual information. In communication with male patients, questions about sexual activity need to be sensitive to cultural, religious, and educational differences. Using vocabulary that is clear, simple, and respectful of the patient's feelings can facilitate communication.

2) From the results of the study, BMI and smoking seem to be manipulated factors influencing QoL. This suggests that healthcare providers should encourage diabetic men with erectile dysfunction to maintain a healthy weight by exercising and eating healthily. In addition, healthcare providers need to encourage smoking reduction or smoking cessation with this population. Healthcare providers should explain to diabetic men with erectile dysfunction that BMI and smoking can lead to a higher severity of DED. Also, nurses should assess other factors associated with QoL in order to support male patients and help them to improve their QoL.

3) The results showed that low quality of life is especially notable in the psychological and social relationship domains. Thus, nurses should give the time and privacy to discuss their concerns about erectile dysfunction. Nurses could offer psychosexual counseling to diabetic men with erectile dysfunction.

4) Qualitative research should be conducted to provide insight into how the severity of DED influences quality of life domains. In addition, exploring the factors affecting the severity of DED is required.

\section{Limitation}

Our study has 2 major limitations. First, the setting of this study was a tertiary hospital in which all subjects in this study were part of a group of treated diabetic patients. Additionally, only diabetic men who had had sexual intercourse within the last 6 months were selected to be subjects in the study. Therefore, the subject recruitment criteria may have biased the prevalence and QoL estimation. The findings of this study cannot be generalized to the prevalence of, and QoL levels of, men with untreated DM. Second, sexuality is a sensitive social issue; thus, the data gathered from the questionnaire may not fully and accurately diagnose men living with DED, due to embarrassment during the survey. We recommend that further study in this area use a private place to conduct data collection.

Despite these limitations, our study is the $1^{\text {st }}$ epidemiological study on DED among male patients living with DM attending diabetic outpatient departments of tertiary hospitals in the northern part of 
http://wjst.wu.ac.th

Thailand. Further investigation on the prevalence of DED in, and QoL of, these men should include various groups of men living with DM, such as untreated DM patients. In particular, different settings that could include men of more varying demographics are recommended.

\section{Conclusions}

This study observed a high frequency of DED among men with diabetes mellitus in Thailand. The presence of DED was $71.65 \%$, with more than half of those affected experiencing a mild intensity of DED. The study also demonstrated that the majority of men with DED had a decreased QoL, especially in the physical and social relationship domains. The most important factors associated with a decline in QoL level were the severity of DED, age, BMI, and smoking, whereas the factors associated with an increase in QoL were performing masturbation and having sexual intercourse. DED screening as a routine clinical practice may be justified, so that adequate consultation and treatment can be offered in order to help patients improve and maintain their QoL.

\section{Acknowledgements}

The authors' research was supported by the National Research Council of Thailand (NRCT). The funding source of this study did not have any role in the study design or in conducting the practical work of writing the report.

\section{References}

[1] ZA Kamenov. A comprehensive review of erectile dysfunction in men with diabetes. Exp. Clin. Endocrinol. Diabetes 2015; 123, 141-58.

[2] D Price. Sexual problems in diabetes. Medicine 2014; 43, 38-40.

[3] VS Thorve, AD Kshirsagar, NS Vyawahare and VS Joshi. Diabetes-induced erectile dysfunction: Epidemiology, pathophysiology and management. J. Diabetes Complications 2011; 25, 129-36.

[4] A Hassan, K Aburisheh, TJ Sheikh, SA Meo, NA Ahmed and AHA Sharaqawi. Prevalence of erectile dysfunction among Saudi type 2 diabetic patients. Eur. Rev. Med. Pharmacol. Sci. 2014; 18, 1048-57.

[5] R Shamloul and H Ghanem. Erectile dysfunction. Lancet 2013; 381, 153-65.

[6] SL Vignera, R Condorelli, E Vicari, R D'agata and AE Calogero. Physical activity and erectile dysfunction in middle-aged men. J. Androl. 2012; 33, 154-61.

[7] JG Ryan and J Gajraj. Erectile dysfunction and its association with metabolic syndrome and endothelial function among patients with type 2 diabetes mellitus. J. Diabetes Complications 2012; 26, 141-7.

[8] K Hatzimouratidis and D Hatzichristou. Erectile dysfunction and diabetes mellitus. Insulin 2009; 4, 114-22.

[9] BG Bokhour, JA Clark, TS Inui, RA Silliman and JA Talcott. Sexuality after treatment for early prostate cancer exploring the meanings of "Erectile dysfunction". J. Gen. Intern. Med. 2001; 16, 649-55.

[10] K Asmara, MM Hengky, F Agustanti and HP Tampubolon. Erectile dysfunction and health-related quality of life in elderly males. J. Taibah Univ. Med. Sci. 2011; 30, 182-8.

[11] A Avasthi, S Grover, A Bhansali, RJ Dash, N Gupta, P Sharan and S Sharma. Erectile dysfunction in diabetes mellitus contributes to poor quality of life. Int. Rev. Psychiatry 2011; 23, 93-9.

[12] TJ Walsh, JM Hotaling, A Smith, C Saigal and H Wessells. Men with diabetes may require more aggressive treatment for erectile dysfunction. Int. J. Impot. Res. 2014; 26, 112-5.

[13] MP McCabe and H Matic. Erectile dysfunction and relationships: views of men with erectile dysfunction and their partners. Sex. Relation Ther. 2008; 23, 51-60.

[14] JC Brooke, DJ Walter, D Kapoor, H Marsh, V Muraleedharan and TH Jones. Testosterone deficiency and severity of erectile dysfunction are independently associated with reduced quality of life in men with type 2 diabetes. Andrology 2014; 2, 205-11. 
http://wjst.wu.ac.th

[15] G De Berardis, M Franciosi, M Belfiglio, B Di Nardo, S Greenfield, SH Kaplan and A Nicolucci. Erectile dysfunction and quality of life in type 2 diabetic patients: A serious problem too often overlooked. Diab. Care. 2002; 25, 284-91.

[16] QK Fatt. Erectile Dysfunction and Quality of Life. In: KP Nunes (Ed.). Erectile DysfunctionDisease-Associated Mechanisms and Novel Insights into Therapy. $2^{\text {nd }}$ (eds.). InTechopen, London, 2012, p. 35-46.

[17] LS Malavige, SD Jayaratne, ST Kathriarachchi, S Sivayogan, P Ranasinghe and JC Levy. Erectile dysfunction is a strong predictor of poor quality of life in men with Type 2 diabetes mellitus. Diab. Med. 2014; 31, 699-706.

[18] MD Mitkov, IY Aleksandrova and MM Orbetzova. Effect of transdermal testosterone or alpha lipoic acid on erectile dysfunction and quality of life in patients with type 2 diabetes mellitus. Folia Medica 2013; 55, 55-63.

[19] G Ali, TA Mahmood, S Fatemeh, B Mahdiye, D Fatemeh, M Farhad, M Kamyar, M Yousef and R Abdolhalim. Application of the World Health Organization quality of life instrument, short (WHOQOL-BREF) to patients with cataract. Epidemiol. Health. 2016; 38, 1-7.

[20] K Hatzimouratidis and D Hatzichristou. How to treat erectile dysfunction in men with diabetes: From pathophysiology to treatment. Curr. Diab. Rep. 2014; 14, 545.

[21] ZA Kamenov. (2015). A comprehensive review of erectile dysfunction in men with diabetes. Exp. Clin. Endocrinol. Diabetes 2015; 123, 141-58.

[22] P Kwangsung, $\mathrm{CH} \mathrm{Eu}$ and $\mathrm{K}$ Sun-Ouck. Prevalence and medical management of erectile dysfunction in Asia. Asian J. Androl. 2011; 13, 543-9.

[23] S Mahatnirunkul, W Tuntipivatanakul and W Pumpisanchai. Comparison of the WHOQOL-100 and the WHOQOL- BREF (26 items). J. Ment. Health Thai 1998; 5, 4-15.

[24] I Ahmed, AH Aamir, E Anwar, SS Ali, A Ali and A Ali. Erectile dysfunction and type 2 diabetes mellitus in northern Pakistan. J. Pak. Med. Assoc. 2013; 63, 1486-90.

[25] G De Berardis, F Pellegrini, M Franciosi, M Belfiglio, B Di Nardo and S Greenfield. Longitudinal assessment of quality of life in patients with type 2 diabetes and self-reported erectile dysfunction. Diab. Care 2005; 28, 2637-43.

[26] DF Penson, DM Latini, DP Lubeck, KL Wallace, JM Henning and TF Lue. Do impotent men with diabetes have more severe erectile dysfunction and worse quality of life than the general population of impotent patients? Results from the exploratory comprehensive evaluation of erectile dysfunction (ExCEED) database. Diab. Care 2003; 26, 1093-9.

[27] JM Tomlinson and D Wright. Impact of erectile dysfunction and its subsequent treatment with sildenafil: Qualitative study. Br. Med. J. 2004; 328, 1037-9.

[28] D Pontin, T Porter and R McDonagh. Investigating the effect of erectile dysfunction on the lives of men: A qualitative research study. J. Clin. Nurs. 2002; 11, 264-72.

[29] S Henninger, C Höhn, C Leiber and MM Berner. Treatment expectations of men with ED and their female partners: An exploratory qualitative study based on grounded theory. Int. J. Impot. Res. 2015; 27, 167-72.

[30] E Wentzell. Masculinity and emotion in Mexican men's understanding of erectile dysfunction aetiology and treatment. J. Res. Inter. Care 2014; 16, 164-77.

[31] WY Low, CJ Ng, WY Choo and HM Tan. How do men perceive erectile dysfunction and its treatment? A qualitative study on opinions of men. Aging Male 2006; 9, 175-80.

[32] C Defillipo. Perpetuating inequality: Homosociality, sexuality, and gendered power structures in Northern Thailand. In: Proceedings of the $13^{\text {th }}$ International Conference on Thai Studies Globalized Thailand? Connectivity, Conflict and Conundrums of Thai Studies. Chiang Mai, Thailand, 2017, p. $1-12$.

[33] O Piayura. The representation of masculinity in Thai contemporary literature. In: Proceedings at the ISER $5^{\text {th }}$ International Conference. Singapore, 2015, p. 43-5.

[34] S Permpongkosol. How sex is important for men. Available at: https://www.dailynews.co.th/article/ 630842, accessed March 2018. 
http://wjst.wu.ac.th

[35] E Iyigun, H Ayhan and S Tastan. Perceptions and experiences after radical prostatectomy in Turkish men: A descriptive qualitative study. Appl. Nurs. Res, 2011; 24, 101-9.

[36] SA McGraw, RC Rosen, SE Althof, M Dunn, A Cameron and D Wong. Perceptions of erectile dysfunction and phosphodiesterase type 5inhibitor therapy in a qualitative study of men and women in affected relationships. J. Sex Marital Ther. 2015; 41, 203-20.

[37] BS Laursan. Sexuality in men after prostate cancer surgery: A qualitative interview study. Scand. J. Caring Sci. 2017; 31, 120-7.

[38] I Peate. Taking a sexual health history: The role of the practical nurse. Br. J. Nurs. 1997; 6, 978-83. 